\title{
Pull-out strength of glued-in GFRP rods in timber connections by using of epoxy resin reinforced by nanoparticles
}

\author{
Mehrab Madhoushi ${ }^{1 * i D}$
}

${ }^{1}$ Gorgan University of Agricultural Sciences and Natural Resources, Gorgan, Iran

\section{TECHNOLOGY OF FOREST PRODUCTS}

\section{ABSTRACT}

Background: In timber structures, connections are the most important and critical section which supply the strength of each structural element. The aim of this study was evaluation the behavior of epoxy resin reinforced by nanoclay (at three levels) on the pull-out strength of glued-in GFRP rods in glulam. For this purpose, two rods with three lengths (50, 150 and $250 \mathrm{~mm}$ ) and diameters $(6.4,12.7$ and $19.1 \mathrm{~mm})$ were inserted at two opposite sides of glulam blocks (with dimension of $8.89 \times 8.89 \times 29.94 \mathrm{~cm}$ ) which were glued by epoxy resin. Samples underwent tensile testing and their tensile strength and shear strength were measured. The obtained data were analyzed statistically and the effects of studied factors on bond strength were evaluated.

Results: The results showed that the strength of bonding increased with the addition of a low amount of nanoclay, and the length of the rod had a greater effect than its diameter. Furthermore, the amount of nanoclay, rod length and diameter could not significantly affect simultaneously, the performance and strength of glued-in GFRP rods

Conclusion: Nanoclay particle can be considered as a reinforcement for epoxy resin in glued-in GFRP rods and its effect may cause a considerable increase in the mechanical strengths of joints.

Keywords: Epoxy resin, Bonding Strength, GFRP, Glulam, Nanoclay

\section{HIGHLIGHTS}

Performance of epoxy resin may be enhanced by nanocaly.

Adding nanoclay to epoxy resin enhances the strength of GFRP rods in glulam.

Strength of joints increases with the addition of a low amount of nanoclay.

Amount of nanoclay and geometry of rod may not affect simultaneously the strength of joint.

MADHOUSHI, M. Pull-out strength of glued-in gfrp rods in timber connections by using of epoxy resin reinforced by nanoparticle. CERNE, v. 27, e-102508, doi: 10.1590/01047760202127012508 


\section{INTRODUCTION}

In timber structures, connections are the most important and critical section which supply the strength of each structural element as well as the stability of the entire structure. Their main role is the absorption and dissipation of the energy induced by loading between the elements which result in the structural stability of the whole building. For these reasons and also safety in service, it is necessary to study and design proper connections.

During the past decades, researchers have focused on the reinforcement of timber joints, by means of glassfiber reinforced plastic (GFRP) and carbon-fiber reinforced plastic (CFRP), to enhance their performance under severe conditions such as fatigue, earthquakes and rehabilitation (Madhoushi and Ansell, 2008; Madhoushi et al. 2011; Raftery and Whelan, 2014). These materials are used as sheets (Raftery and Harte, 2011; Corradi et al., 2016) or as glued-in rods (Bainbridge et al., 2002; Tlustochowicz et al., 2011). The axial and shear strength of joints made with glued-in rods depends on several factors such as resin type, reinforcing material, joints configuration, curing time, glueline thickness and service conditions (Feligioni et al., 2003; Steiger et al., 2007). For example, larger thickness of glueline has more stress rate effect and is more susceptible to fatigue loadings (Madhoushi and Ansell, 2004; Madhoushi and Ansell, 2017) or length of glue-line has a positive effect on the final strength of the joint (Broughton and Hutchinson, 2001).

Recently, nanotechnology and nanomaterials have provided new opportunities in these regards, and new epoxy-based nanocomposites have been introduced and evaluated (Azeez et al., 2013; Gupta et al., 2007; Gurusideswar et al., 2016; Albdiry et al., 2013; Ferreira et al., 2013). With respect to timber joints, adding nanomaterials (in a very low amount percentage) to bonding agents, generally, showed considerable effect on enhancing the strength of joints, because of their positive effect on the interface of timber and glue (Ahmad et al., 2010).

Among the nanomaterials, utilization of nanoclay as reinforcement for polymer has shown an increasing trend in global marketing with an expectation of worth US\$3,369.3 $\mathrm{mn}$ by 2023 (US\$1,222.0 mn: in 2014) due to commercialization of nanoclay-reinforced polymers and reduction of the price of the final products (Transparency Market Research, 2015).

In particular, nanoclay reinforced epoxy resin has demonstrated a considerable performance on mechanical strength and fracture toughness of resin (Wang et al., 2005; Miyagawa and Drazal, 2004). As a result of their high intercalation chemistry and aspect ratio (Azeez et al., 2013), its influence could be affected by the amount of nanoclay and processing of nanocomposites. However, the fatigue strength of nanoclay/epoxy resin may decrease in comparison with neat resin (Ferreira et al., 2013). Another study showed that reinforced epoxy resin, with $5 \%$ wt. of nanoclay, may improve the Young's modulus and tensile strength of a resin film up to $34 \%$ and $25 \%$, respectively (Chan et al., 2011). They indicated that nanoclay could improve the mechanical strength of the composites because the formation of boundaries between the nanoclay clusters and resin can modify the matrix grains.

In general, nanoclay in polymeric matrix can exist in three different states, namely agglomerated, intercalated and exfoliated, which the last one may have better and significant effect on the storage modulus, Young's modulus and fracture toughness of final composites (Gajjela et al., 2016, Park et al., 2003; Zhou et al., 2008). It has also been reported that adding low percentages of nanoclay to epoxy resin can improve its impact resistance and reduce the physical damage (Balaganesan et al. 2014; Rafig et al., 2017). This feature can be very important in designing wooden joints where impact resistance is important. Because, the previous researches demonstrated that epoxy resin containing nanoclay can absorb more energy under dynamic loading and improve fracture toughness (Domun et al. 2015; Liu et al. 2005).

Regarding the utilization of nanoclay/epoxy resin in timber joints, there is very limited published work and the author could not access any such study, especially in gluedin rods. The aim of this study was evaluation the behavior of epoxy resin reinforced by nanoclay on the tensile and shear strength of glued-in GFRP rods in glulam. It was supposed that nanoclay may enhance the glued-in rods strength, and the rod dimensions may affect this strength.

\section{MATERIAL AND METHODS}

Glulam blocks (made of Scots pine, Pinus sylvestris) were selected with dimensions of $27.94 \mathrm{~cm}$ (11 in) in length and cross section of 8.89 by $8.89 \mathrm{~cm}$ (3.5 by $3.5 \mathrm{in}$ ). GFRP rods were inserted in glulam longitudinally (parallel to grain) and from two opposite sections (Fig. 1). Three lengths, namely 50,150 and $250 \mathrm{~mm}$ and three rod diameters, namely 6.4, 12.7 and $19.1 \mathrm{~mm}$ (2/8, 4/8 and 6/8 in) were considered (Zhu et al., 2017) (Tab. 1). The main process of manufacturing of the samples of glue-in GFRP rods was conducted according to the method of Madhoushi and Ansell (2004).

The commercially available Cold Cure Epoxy resin, was reinforced by nanoclay, Closite $30 \mathrm{~B}{ }^{\circledR}$, at three levels, 0 ,

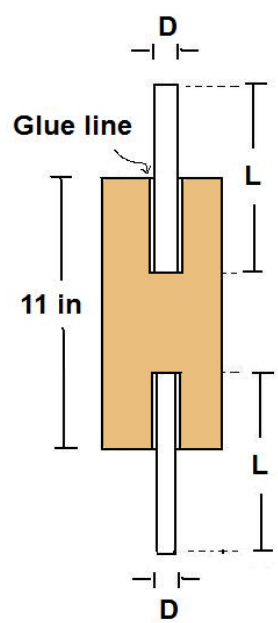

Fig. 1 Schematic view of sample, showing two GFRP rods were inserted in glulam longitudinally (parallel to grain) and from two opposite sections. Glue-line contains epoxy resin/nanoclay. L= length of rod, $\mathrm{D}=$ diameter of rod. 
Tab. 1 Treatment table for testing.

\begin{tabular}{|c|c|c|c|c|c|c|c|c|c|c|}
\hline \multirow{3}{*}{ No. } & \multirow{3}{*}{$\begin{array}{c}\text { Treatment } \\
\text { Code }\end{array}$} & \multicolumn{3}{|c|}{ Rod length (mm) } & \multicolumn{3}{|c|}{ Rod diameter (mm) } & \multicolumn{3}{|c|}{ Nanoclay (\%) } \\
\hline & & 0 & 1 & 2 & 6.4 & 12.7 & 19.1 & 50 & 150 & 250 \\
\hline & & NO & N1 & $\mathrm{N} 2$ & D1 & D2 & D3 & $\mathrm{L} 1$ & $\mathrm{~L} 2$ & पL3 \\
\hline 1 & N0D1L1 & * & & & * & & & $*$ & & \\
\hline 2 & N0D1L2 & * & & & * & & & & * & \\
\hline 3 & N0D1L3 & * & & & * & & & & & * \\
\hline 4 & N0D2L1 & * & & & & * & & * & & \\
\hline 5 & N0D2L2 & * & & & & * & & & * & \\
\hline 6 & NOD2L3 & * & & & & * & & & & * \\
\hline 7 & N0D3L1 & * & & & & & * & * & & \\
\hline 8 & N0D3L2 & * & & & & & * & & * & \\
\hline 9 & N0D3L3 & * & & & & & * & & & * \\
\hline 10 & N1D1L1 & & * & & * & & & * & & \\
\hline 11 & N1D1L2 & & * & & * & & & & * & \\
\hline 12 & N1D1L3 & & * & & * & & & & & * \\
\hline 13 & N1D2L1 & & * & & & * & & * & & \\
\hline 14 & N1D2L2 & & $\star$ & & & * & & & * & \\
\hline 15 & N1D2L3 & & * & & & * & & & & * \\
\hline 16 & N1D3L1 & & * & & & & * & * & & \\
\hline 17 & N1D3L2 & & $\star$ & & & & * & & * & \\
\hline 18 & N1D3L3 & & * & & & & * & & & * \\
\hline 19 & N2D1L1 & & & $\star$ & * & & & * & & \\
\hline 20 & N2D1L2 & & & * & * & & & & * & \\
\hline 21 & N2D1L3 & & & $\star$ & * & & & & & * \\
\hline 22 & N2D2L1 & & & * & & * & & * & & \\
\hline 23 & N2D2L2 & & & $\star$ & & * & & & * & \\
\hline 24 & N2D2L3 & & & * & & * & & & & * \\
\hline 25 & N2D3L1 & & & * & & & * & * & & \\
\hline 26 & N2D3L2 & & & * & & & * & & * & \\
\hline 27 & N2D3L3 & & & * & & & * & & & * \\
\hline
\end{tabular}

1 and $2 \%$ wt, by using a mixture at $1000 \mathrm{rpm}$ for $1 \mathrm{~h}$ at room temperature. The mixing speed and time were selected based on preliminary investigations.

In order to insert the rods inside of glulam, two holes were drilled at both end sections of the samples followed by filling of the holes with resin, and a glue-line thickness of $1.6 \mathrm{~mm}$ (1/16 in) was obtained. GFRP rod were inserted into the sample with a twisting action. The twisting action allowed even distribution of the adhesive (Madhoushi and Ansell, 2004). From each treatment, three replications were considered for statistical analysis.

Prepared samples were kept between clamps for 72 $\mathrm{h}$ in order to achieve resin curing and finally, their moisture content was measured by means of a portable electrical moisture meter.

Then, the pull-out testing of samples was evaluated by an Instron Universal Testing at loading speed of $2 \mathrm{~mm}$ / min. After obtaining the data, the tensile and shear stresses of the joints were respectively calculated with the following equations: [1], [2], where, $\sigma_{\mathrm{t}}=$ tensile stress $(\mathrm{Pa}), \tau_{\text {ra }}=$ shear stress $(\mathrm{Pa}), \mathrm{F}_{\mathrm{t}}=$ maximum load $(\mathrm{N}), \mathrm{r}=\operatorname{rod}$ radius $(\mathrm{m})$, $\mathrm{I}=$ rod length $(\mathrm{m}), \mathrm{t}=$ glue-line thickness $(\mathrm{m})$.

$$
\sigma_{t}=\frac{F_{t}}{\pi r^{2}}
$$

$$
\tau_{r a}=\frac{F_{t}}{2 \pi r l}
$$

Then, the average of tensile stress and shear stress of joints were calculated and analyzed by means of ANOVA methods using SPSS software and the statistical effects of studied factors were investigated using full factorial method. Duncan test was also used for statistical comparison between the average of strengths.

\section{RESULTS AND DISCUSSION}

\section{General output}

Stat Statistical analysis (ANOVA) showed that rod diameters, rod length and percentage of nanoclay in epoxy resin may significantly affect the maximum loads, tensile and shear stress of glued-in GFRP rods (Tab. 2). However, the pattern of influence is different depending on the properties. The addition of nanoclay to epoxy resin tends to increase both the tensile and shear stresses (Fig. 2). The effect of each of the studied factors is presented separately in the following sections. 
Tab. 2 Analysis of variance on the effects of nanoclay and rod dimensions and their interaction on tensile and shear stress of GFRP glue-in rods.

\begin{tabular}{|c|c|c|c|c|c|c|}
\hline Source & Dependent Variable & Type III Sum of Squares & $\mathrm{df}$ & Mean Square & $\mathrm{F}$ & Sig. \\
\hline \multirow{2}{*}{ Nano } & Tensile Stress & 131934.452 & 2 & 65967.226 & 451.961 & 0.000 \\
\hline & Shear Stress & 58.511 & 2 & 29.255 & 256.319 & 0.000 \\
\hline \multirow{2}{*}{ Diam } & Tensile Stress & 2574328.247 & 2 & 1287164.123 & 8818.747 & 0.000 \\
\hline & Shear Stress & 21.634 & 2 & 10.817 & 94.774 & 0.000 \\
\hline \multirow{2}{*}{ Length } & Tensile Stress & 888169.956 & 2 & 444084.978 & 3042.559 & 0.000 \\
\hline & Shear Stress & 403.429 & 2 & 201.714 & 1767.314 & 0.000 \\
\hline \multirow{2}{*}{ Nano * Diam } & Tensile Stress & 69529.766 & 4 & 17382.442 & 119.092 & 0.000 \\
\hline & Shear Stress & 2.791 & 4 & 0.698 & 6.112 & 0.000 \\
\hline \multirow{2}{*}{ Nano * Length } & Tensile Stress & 6490.726 & 4 & 1622.682 & 11.117 & 0.000 \\
\hline & Shear Stress & 14.727 & 4 & 3.682 & 32.257 & 0.000 \\
\hline \multirow{2}{*}{ Diam * Length } & Tensile Stress & 213094.104 & 4 & 53273.526 & 364.993 & 0.000 \\
\hline & Shear Stress & 12.579 & 4 & 3.145 & 27.554 & 0.000 \\
\hline \multirow{2}{*}{ Nano * Diam * Length } & Tensile Stress & 7748.150 & 8 & 968.519 & 6.636 & 0.000 \\
\hline & Shear Stress & 0.597 & 8 & 0.075 & 0.654 & 0.729 \\
\hline \multirow{2}{*}{ Error } & Tensile Stress & 7881.716 & 54 & 145.958 & & \\
\hline & Shear Stress & 6.163 & 54 & 0.114 & & \\
\hline \multirow{2}{*}{ Total } & Tensile Stress & 13181863.511 & 81 & & & \\
\hline & Shear Stress & 4401.850 & 81 & & & \\
\hline \multirow{2}{*}{ Corrected Total } & Tensile Stress & 3899177.118 & 80 & & & \\
\hline & Shear Stress & 520.431 & 80 & & & \\
\hline
\end{tabular}

\section{Nanoclay effect}

Increasing nanoclay from 0 to $1 \%$ results to $23.57 \%$ and $23.48 \%$ increase in tensile and shear stress, respectively. Furthermore, increasing nanoclay from 1 to $2 \%$ results to 10.65 and $9.5 \%$ increase in tensile and shear stress, respectively. This finding has revealed that increasing the nanoclay from 0 to $1 \%$ has more influence on the mechanical strength of joints compared to increasing it from 1 to $2 \%$. In other words, at first a faster slope can be seen when the mechanical strength is increased followed by a slower slope in the trend of increasing. This phenomenon might be related to more agglomeration of nanoclay particles in the matrix of the resin at higher amount of nanoparticles and lower resin-clay surface interaction (Azeez et al., 2013; Ferreira et al., 2013). Numerous studies have shown that adding a very small amount of nanoparticles to a polymeric substrate has a positive effect on mechanical properties, but adding a large amount of nanoparticles reduces the mechanical properties due to particle agglomeration. This phenomenon was also observed in this study and the strength properties of the resin and, consequently, the connection strength, improved at lower percentages of nanoparticles compared to higher values.

\section{Rod dimensions effect}

Similarly, rod length has a significantly positive effect on tensile strength (Fig. 3), but its effect on shear strength is decreasing (Zhu et al., 2017). Furthermore, both tensile stress and shear stresses are reduced as the rod diameter increases (Fig. 4). This is in accordance with the previous experimental findings (Madhoushi and Ansell, 2004) and finite element analysis (Madhoushi and Ansell, 2017) for single glued-in rod. These findings indicate well that the rod length has a more significant effect on the connection strength compared to its diameter. However, for multiple glued-in rods this issue needs further investigation.

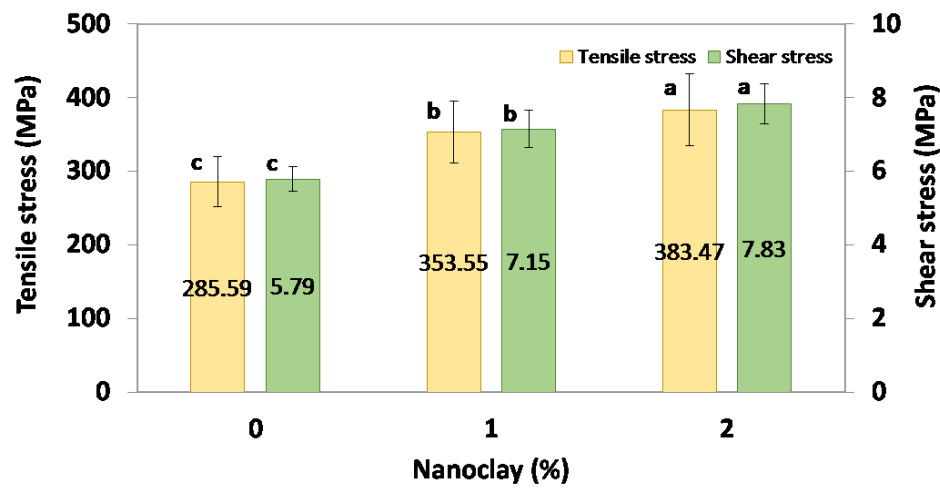

4
Fig. 2 Effect of nanoclay in epoxy resin on pull-out strength of glued-in GFRP rods (The letter above the histogram indicates Duncan grouping). 

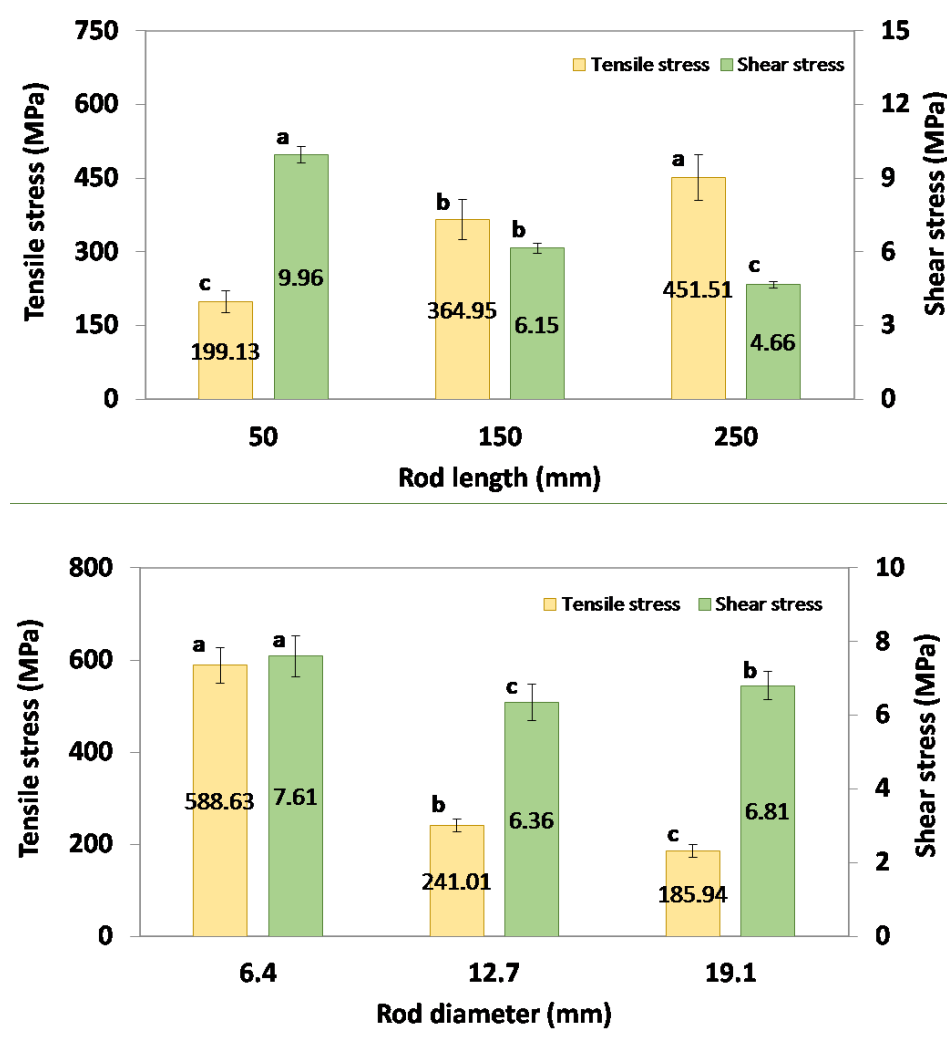

Fig. 3 Effect of rod length on pull-out strength of glued-in GFRP rods (The letter above the histogram indicates Duncan grouping).
Fig. 4 Effect of rod diameter on pull-out strength of glued-in GFRP rods (The letter above the histogram indicates Duncan grouping).

\section{Interaction between factors}

Also, statistical analysis revealed that there are not interactions between the studied factors where nanoclay exists (Tab. 2). In other words, reinforced epoxy resin by nanoclay, rod length and diameter may significantly affect the performance and strength of glued-in GFRP rods. According to the results, to increase the mechanical strength, nanoclay can be added to the epoxy resin in amount of 1-2\% wt (Azeez et al., 2013), but the effect of adding more nanoclay requires further investigations. In addition, in order to have a better performance with reinforced epoxy in glued-in GFRP rods, it is suggested that slightly longer rods with smaller diameters be used.

\section{Final output}

These findings indicate that nanoclay particle can be considered as a reinforcement for epoxy resin in gluedin GFRP rods and its effect may cause a considerable increase in the mechanical strengths of joints. However, it is suggested to investigate deeply the effect of other amounts of nanocaly in resin.

\section{CONCLUSION}

From the finding of this research, it can be concluded that the new reinforced epoxy resin by nanoclay particles, has good compatibility with wood and GFRP rod. Moreover, in glued-in rods, tensile and shear stress are increased with the addition of a small amount of nanoclay (1 to $2 \%$ ).
Amount of nanoclay, rod length and diameter may not simultaneously affect the performance and strength of the glued-in GFRP rods, significantly based on ANOVA analysis.

\section{ACKNOWLEDGEMENT}

The author gratefully acknowledges the financial support from the research deputy of Gorgan University of Agricultural Sciences and Natural Resources.

\section{AUTHORSHIP CONTRIBUTION}

Project Idea: MM

Funding: MM

Database: MM

Processing: MM

Analysis: $\mathrm{MM}$

Writing: MM

Review: MM

\section{REFERENCES}

AAHMAD, Z:; ANSELL, M. P.; SMEDLEY, D. Epoxy adhesives modified with nano- and microparticles for in situ timber bonding: Effect of environment on mechanical properties and moisture uptake. Journal of Engineering Materials and Technology, v. 132, n. 3, p. 031016-031018, 2010

ALBDIRY, M.; YOUSIF, B.; KU, H.; LAU, K. A critical review on the manufacturing processes in relation to the properties of nanoclay/polymer composites. Journal of Composite Materials, v. 47, n. 9, p. 1093-1115, 2013. 
AZEEZ, A. A.; RHEE, K. Y.; PARK, S. J.; HUI, D. Epoxy clay nanocomposites. .processing, properties and applications: A review. Composites Part B: Engineering, v. 45, n. 1, p. 308-320, 2013.

BAINBRIDGE, R.; METTEM, C.; HARVEY, K.; ANSELL, M. Bonded-in rod connections for timber structures-development of design methods and test observations. International Journal of Adhesion and Adhesives, v. 22, n. 1, p. 47-59, 2002.

Balaganesan, G., Velmurugan, R., Srinivasan, M., Gupta, N.K., Kanny, K. Energy absorption and ballistic limit of nanocomposite laminates subjected to impact loading, International Journal of Impact Engineering, v. 74, p. 57-66, 2014

BROUGHTON, J. G.; HUTCHINSON, A. R. Pull-out behaviour of steel rods bonded into timber. Materials and Structures, v. 34, n. 2, p. 100-109, 2001.

CHAN, M.-L.; LAU, K.-T.; WONG, T. T.; CARDONA, F. Interfacial bonding characteristic of nanoclay/polymer composites. Applied Surface Science, v. 258, n. 2, p. 860-864, 2011.

CORRADI, M.; BORRI, A.; CASTORI, G.; SPERANZINI, E. Fully reversible reinforcement of softwood beams with unbonded composite plates. Composite Structures, v. 149, p. 54-68, 2016.

DOMUN, N., HADAVINIA, H., ZHANG, T., SAINSBURY, T. LIAGHAT, G. H., VAHIDA, S. Improving the fracture toughness and the strength of epoxy using nanomaterials - a review of the current status. Nanoscale, 7, 10294, 2015.

FELIGIONI, L.; LAVISCI, P.; DUCHANOIS, G.; DE CIECHI, M.; SPINELLI, P. Influence of glue rheology and joint thickness on the strength of bonded-in rods. Holz als Roh- und Werkstoff, v. 61, n. 4, p. 281-287, 2003

FERREIRA J. A $M$ : BORREGO, L. P: COSTA J D $M$ : CAPELA, $C$ Fatigue behaviour of nanoclay reinforced epoxy resin composites. Composites Part B: Engineering, v. 52, p. 286-291, 2013.

GAJJELA, S., RAMACHANDRAN, V., SOMASEKHARAN, J. Influence of interphase material and clay particle shape on the effective properties of epoxy-clay nanocomposites. Composites Part B: Engineering, v. 88, p. 11-18, 2016

GUPTA, N.; LIN, T. C.; SHAPIRO, M. Clay-epoxy nanocomposites: Processing and properties. JOM, v. 59, n. 3, p. 61-65, 2007

GURUSIDESWAR, S.; VELMURUGAN, R.; GUPTA, N. K. High strain rate sensitivity of epoxy/clay nanocomposites using non-contact strain measurement. Polymer, v. 86, p. 197-207, 2016.

LIU, W., HOA, S. V., PUGH, M. Fracture toughness and water uptake of highperformance epoxy/nanoclay nanocomposites, Composites Science and Technology, v 65, p. 15-16, 2005

MADHOUSHI, M.; ANSELL, M. P. Experimental study of static and fatigue strengths of pultruded GFRP rods bonded into LVL and glulam. Internationa Journal of Adhesion and Adhesives, v. 24, n. 4, p. 319-325, 2004.
MADHOUSHI, M.; ANSELL, M. P. Behaviour of timber connections using glued-in GFRP rods under fatigue loading. Part II: Moment-resisting connections. Composites Part B: Engineering, v. 39, n. 2, p. 249-257, 2008.

Madhoushi, M.; Sadatzadeh, S.; Ebrahimi, Gh. Reinforcement of bolted timber joints using GFRP sheets in poplar and pine woods, Iranian Journal of Polymer Science and Technology, v. 24, n. 3, p. 171-179, 2011.

MADHOUSHI, M.; ANSELL, M. P. Effect of glue-line thickness on pull-out behavior of glued-in GFRP rods in LVL: Finite element analysis. Polymer Testing, v. 62, p. 196-202, 2017.

MIYAGAWA, $\mathrm{H}_{\text {.; }}$ DRZAL, L. T. The effect of chemical modification on the fracture toughness of montmorillonite clay/epoxy nanocomposites. Journa of Adhesion Science and Technology, v. 18, n. 13., p. 1571-1588, 2004.

TRANSPARENCY MARKET RESEARCH. Nanoclay Market (Kaolinite, Smectite, and Others) Market for Packaging, Flame Retardants, Automotive, Paints \& Coatings, and Other End-users, Global Industry Analysis, Size, Share, Growth, Trends and Forecast, 2015-2023. https://www.transparencymarketresearch.com, 2015

PARK, J. H.; JANA, S. C. Mechanism of exfoliation of nanoclay particles in epoxy-clay nanocomposites. Macromolecules, v. 36, n. 8, p. 2758-2768, 2003.

RAFIQ, A., MERAH, N., R., AL-QADHIA, M. Impact resistance of hybrid glass fiber reinforced epoxy/nanoclay composite. Polymer Testing, v. 57, p. 1-11, 2017

RAFTERY, G. M.; HARTE, A. M. Low-grade glued laminated timber reinforced with FRP plate. Composites Part B: Engineering, v. 42, n. 4, p. 724-735, 2011.

RAFTERY, G. M.; WHELAN, C. Low-grade glued laminated timber beams reinforced using improved arrangements of bonded-in GFRP rods. Construction and Building Materials, v. 52, p. 209-220, 2014.

STEIGER, R.; GEHRI, E.; WIDMANN, R. Pull-out strength of axially loaded steel rods bonded in glulam parallel to the grain. Materials and Structures, v. 40 n. 1, p. $69-78,2007$

TLUSTOCHOWICZ, G.; SERRANO, E.; STEIGER, R. State-of-the-art review on timber connections with glued-in steel rods. Materials and Structures, v. 44 n. 5, p. 997-1020, 2011

WANG, K.; CHEN, L.; WU, J.; TOH, M.L.; HE, C.; YEE, A. F. Epoxy nanocomposites with highly exfoliated clay: Mechanical properties and fracture mechanisms. Macromolecules, v. 38, n. 3, p. 788-800, 2005.

ZHOU, G.; MOVVA, S: LEE, L. J. Nanoclay and long-fiber-reinforced composites based on epoxy and phenolic resins. Journal of Applied Polymer Science, v. 108, n. 6. p. 3720-3726, 2008

ZHU, $H_{\text {. }}$ FAGHANI, P: TANNERT, T. Experimental investigations on timber joints with single glued-in FRP rods. Construction and Building Materials, v. 140, p. $167-172,2017$ 